\title{
Digital Analysis and Development of Ride-through Capability of AC Contactor with Respect to Voltage Sag Characteristics
}

\author{
Noor Azila Ismail,Linda Mohd Kasim, Nor Fadzilah \\ Mokhtar,Tuan Syahirah Tuan Yaakub \\ Faculty of Electrical Engineering \\ Universiti Teknologi MARA Malaysia \\ noorazila687@ppinang.uitm.edu.my
}

\author{
Hazlie Mokhlis \\ Faculty of Electrical Engineering \\ University Malaya \\ Kuala Lumpur, Malaysia \\ hazli@um.edu.my
}

\begin{abstract}
This paper presents the development of digital simulator tool for sensitivity analysis of ac contactor with respect to voltage sag characteristics. The simulator tool allows varying of the sag characteristics for the purpose of evaluating the behavior of ac contactor under very worst conditions of voltage sags. Describing voltage sag characteristics by their magnitude and duration only without consideration of other parameters is no longer suitable to fully assess the equipments sensitivity. Therefore, this paper presents the necessity to include the point-on-wave of sag initiation and phase shift of sag to explain the sensitivity of ac contactor during sags. From the simulation results, the ride through capability curve is constructed to identify ac contactor sensitivity levels. The curve has demonstrated a rather complex behavior of the ac contactor. By having a simulator tool, ac contactor analysis can be simulated for any type of configurations without having to perform laboratory experiments.
\end{abstract}

Keywords-digital analysis; simulatior tool; ac contactor; voltage sag;ride-through

\section{INTRODUCTION}

Switching elements are essential for efficient control, isolation, protection and signaling in all electrical systems. Among other applications, contactors make possible to centralized or remote control of motor and other industrial machinery. The most important ac contactors are designed to disconnect the load or circuit they control when the main power is intentionally interrupted. However, problems may occur when ac contactors unnecessarily disconnected during power disturbances even though the load (motor) has a ride through the power disturbances. In order to avoid tripping of a large process, the existence of a significant amount of ac contactor is needed and consideration should also be taken on the characteristics of its sensitivity.

This paper focuses on the voltage sag because it is recognized as the most important power quality problems affecting industrial consumers [1]. It can cause the most sensitive equipment to malfunction, thus affecting industrial production process, which leads to revenue loss. The combination of voltage sag and sensitive equipment may cause significant economic impact when resulting in process failure.
Sensitivity of ac contactors to voltage sags is usually expressed as a ride through capability curve, in terms of only one pair of sag magnitude and duration values. These two values are denoted as the threshold values. If the voltage sag is longer than a specific duration threshold and deeper than the specific voltage magnitude threshold, the ac contactor will malfunction. However, the use of magnitude and duration threshold values cannot be applied for the full assessment of ac contactors sensitivity to voltage sag characteristics.

References [2] - [4] report the results of experiment of the sensitivity ac contactor without taking into account all the voltage sag characteristics of influence simultaneously. Therefore, the main focus of this paper is to study the impact of sag magnitude, sag duration, point-on-wave of sag initiation and phase shift of sag simultaneously on ac contactors behavior.

In an ever-growing technology, the task of gathering information on voltage sag characteristics and impact to ac contactor will be impossible if a tool to facilitate this task is not available. According to reference [5], the behavior of ac contactor is studied by extensive conducted laboratory test. Therefore, this will be the main focus of this paper to propose a simulator tool to analyze the performance of an ac contactor. The successful development of this paper is based on simulation tool using PSCAD/EMTDC software [6]. Through digital simulation sensitivity analysis of ac contactor, the results can explain why an ac contactor failed during specific sag characteristics or predict how well an ac contactor will perform during an actual sag event.

\section{AC CONTACTOR}

\section{A. General Principle}

The ac contactor which are often used to control electrical machines, to establish, support and switch off current in one or more electrical circuits by means of separable contacts. They are used when insulation between the load and power source is needed.

The general principle is very simple, which is when the current from the power supply flows to the coil, the moving magnet (armature) of the electromagnet is attracted to the fixed magnet (frame). The armature is spring loaded so as to cause the armature to move away from the frame when the electric signal is not present on the coil. The armature is also linked to the moving contact and causes the fixed contact to 
engage and disengage depending on the strength of the magnetic field. The magnetic force will be produced by contactor coil that offsets the spring force and then causes the contact to engage. For discussion purposes we will assume normally close (NC) contacts [7]. The magnetic force must be sufficient to make electrical contacts to remain engaged or else it will be disengaged.

The ac contactor coils have a number of insulated turns of wire in order to give the necessary Ampere Turn (AT) to operate on small current. The coil voltage is an important consideration in designing an ac contactor. The ac contactors are designed to operate with a specific coil voltage but the design also ensures that they will disengage if the coil voltage drops below some level during sag events. The minimum coil voltage required to keep the ac contactor engaged if the ac contactor is already engaged is called the Minimum Steady State Hold-in Voltage (MSSHIV) [8]. The MSSHIV is important because it provides a baseline to compare contactors performance during sag events.

Fig. 1 shows the geometry diagram that enables to better understand the functional behavior of ac contactor.

\section{B. Electro-Magnetic Equations}

According to reference [9], the development of ac contactor is based on few mathematical equations as follows:

1) The instantaneous flux

$$
\phi=\frac{\mu_{0} \mu_{\mathrm{r}} \mathrm{NIA}}{1_{\mathrm{c}}} \cos (\varpi \mathrm{t})
$$

2) The instantaneous magnetic force

$$
F=\frac{\phi^{2}}{2 \mu_{\mathrm{O}} \mathrm{A}}
$$

Where

$\mathrm{N}=$ number of winding in the coil

$\mathrm{I}=$ current flow through the coil

$l_{c}=$ the length of magnetic path

$\mu_{0}=$ absolute permeability $=m H / 1047-\times \pi$

$\mu_{\mathrm{r}}=$ relative permeability of the coil substances

$\mathrm{A}=$ the cross sectional area of the air gap

For shaded ac contactor, flux for shaded pole, $\phi_{\mathrm{S}}$ will induce the current in the shading ring. The resulting current generates a reaction flux and the net effect is that $\phi_{\mathrm{S}}$ lags the main flux, $\phi_{\mathrm{m}}$. The vector differences between these two fluxes produce the unshaded flux, $\phi_{\mu}$. The leading and lagging phase shift are given by $\beta$ and $\alpha$. Thus, the instantaneous magnetic force shaded ac contactor can be expressed by [10]:

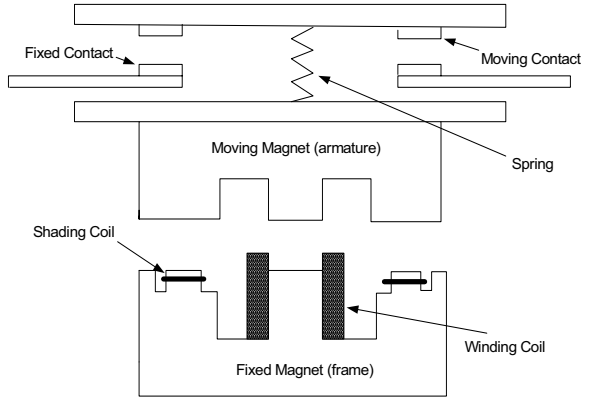

Figure 1. The Geometry Diagram of AC Contactor (Vertical-action)

3) The force for shaded ac contactor

Where:

$$
\mathrm{F}=\frac{1}{2 \mu_{0} \mathrm{~A}_{\mathrm{S}}} \phi_{\mathrm{S}}^{2} \operatorname{cow}^{2}(\varpi \mathrm{t}-\alpha)+\frac{1}{2 \mu_{0} \mathrm{~A}_{\mathrm{u}}} \phi_{\mathrm{u}}^{2} \operatorname{cow}^{2}(\varpi \mathrm{t}+\beta)
$$

$\mathrm{Au}=$ area of the unshaded poles

$\phi_{\mathrm{u}}=$ unshaded flux

As $=$ area of the shaded poles

$\phi_{\mathrm{S}}=$ shaded flux

$\beta$ and $\alpha=$ angle of phase shifts

The development of the ac contactor model is also based on the mechanical proprieties of a real ac contactor. Some of the parameters must be measured from the set of experiment [4] whenever the parameters are not obtainable from the manufacturer's information. The parameters are as follows:

1. Spring force, $\mathrm{Fs}=26.95 \mathrm{~N}$

2. Number Of winding, $\mathrm{N}=5900$

3. Coil resistance, $\mathrm{R}=900 \Omega$

4. Length of magnetic path, $L=0.035 \mathrm{~m}$

5. Unshaded area, $\mathrm{Au}=0.000018 \mathrm{~m}^{2}$

6. Shaded area, As $=0.00003896 \mathrm{~m}^{2}$

\section{MODELING}

\section{A. Sag Generator Model}

The sag generator model that is created by researcher [4] using PSCAD software has been modified. The existing sag generator is not compatible to varying the point-on-wave of sag initiation and phase shift of sag, but it varies the magnitude and duration of sag only. Therefore, a new sag generator model is created to vary the sag magnitude, sag duration, point-on-wave of sag initiation and phase shift of sag. An example of voltage sag event waveform produced by a sag generator will appear in Graph Frame as shown in Fig. 2.

\section{B. AC Contactor Model}

A paper by Hasmaini M. and Khalid M. Nor [4] presents the development of ac contactor circuit as shown in Fig. 3. The resistor and inductor represent the coil impedance and the contact indicates the switch/contact of the ac contactor. The sag generator model is applied to inject the voltage sag to the circuit. On the other hand, the resistive load represents lamp resistance, which is connected to the ac contactor circuit. 


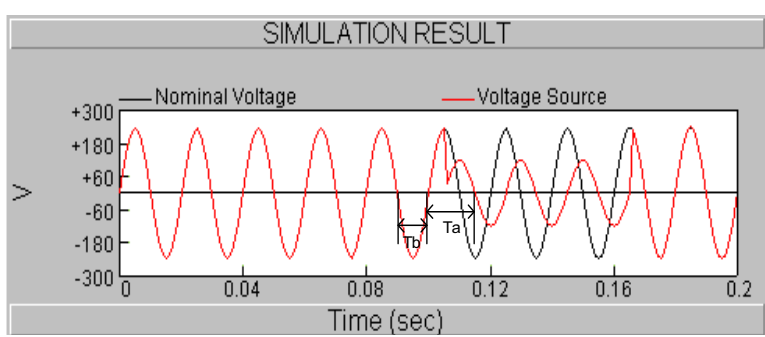

Figure 2. Voltage sag initiated at $90^{\circ}$ and $-90^{\circ}$ phase shift

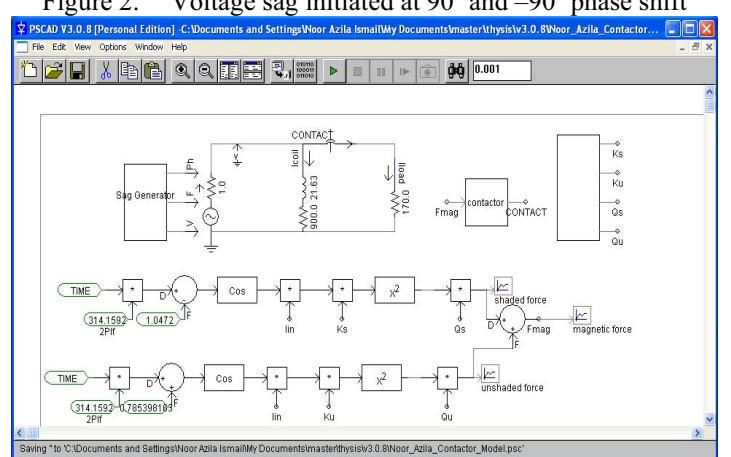

Figure 3. The PSCAD/EMTDC circuit model of sag generator and ac contactor

The ac contactor custom model development is divided into two main parts: 1) the magnetic force production based on mathematical equations (1) - (3) using Continuous System Model Function (CSMF) Digital and Analog Control Block Module of PSCAD Master Library, 2) the contact custom model is developed as a function to control the status of contact. If the contactor is engaged, the contact is close or denote as contact $=0$, or else contact is open $($ contact $=1)$.

This model is developed based on the real ac contactor working principle where the ac contactor will start to disengage if the supply voltage drops in which the minimum value of the magnetic force (Fmag) is less than the spring force (Fs). The spring force value is a constant value obtained from the measurement.

\section{Simulation Of AC CONTACTOR}

\section{A. List of Simulation}

$\mathrm{AC}$ contactor was simulated against the ideal sine wave of voltage sags. Which was the first tested against the impact of sag magnitude and duration. The second was tested against the impact of point-on-wave of sag initiation. The third was tested against the impact of phase shift of sag and finally, is tested against the impact of point-on-wave and phase shift simultaneously. The simulations were conducted to establish the ride through capability of an ac contactor rated at $240 \mathrm{~V} / 50 \mathrm{~Hz}$

\section{B. Simulation Results}

\section{1) Case 1- The impact of sag magnitude and duration}

A simulation was conducted to establish the MSSHIV. The MSSHIV is determined by gradually decreasing the magnitude and duration of sag until the ac contactor is disengaged. It is important because it provides a baseline to compare ac contactor behavior during sags in which pointon-wave and phase shift are introduced.

Fig. 4 shows some of these results. Fig. 4(a) shows the voltage source and coil current waveform when voltage drops to $50 \%(120 \mathrm{~V})$ at $0.1 \mathrm{~s}$ and recovers at $0.3 \mathrm{~s}$. Fig. 4(b) displays the status of contact signal that changes from 'close' to 'open' state when the magnetic force value drops below the constant spring force value. This ac contactor will remain disengaged and unchanged even when the sag recovers to the nominal voltage.

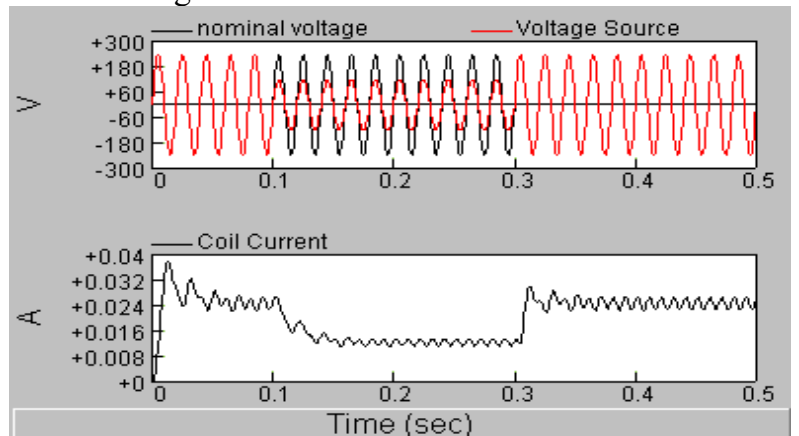

(a) Voltage source and coil current waveform

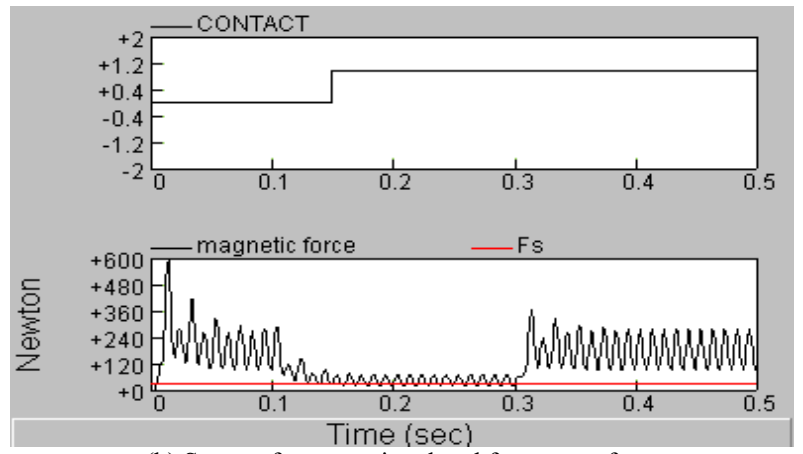

(b) Status of contact signal and force waveform

Figure 4. Sample of simulation results

The tables below describe the simulation results (see TABLE I). Sign ' $E$ ' denotes the 'engage' result and sign ' $D$ ' denotes the 'disengage' result. In order to better understand the ac contactor performance, the ride through capability curve is drawn to display the MSSHIV. SEMI F47 standard [11] is used. The ride through capability curve is drawn when a few points are selected from the simulation result as exhibited in TABLE I. The points at the border outside the highlighted area indicate the selected points representing a border of 'pass' through ac contactor of sag events.

The ride through capability curve for this case is shown in Fig. 5. From this curve, MSSHIV value for the ac contactor is $130 \mathrm{~V}$ or $54.17 \%$ at its rated $240 \mathrm{~V}$ with $0.065 \mathrm{~s}$ minimum duration. The result implies that for any voltage sag duration with magnitude less than $54.17 \%$, the ac contactor will start to disengage. This voltage sag value is the critical value, which determined the sensitivity level of voltage sag. It is observed that the results in this simulation are exactly the same as the experiment results conducted by previous researcher [4]. 


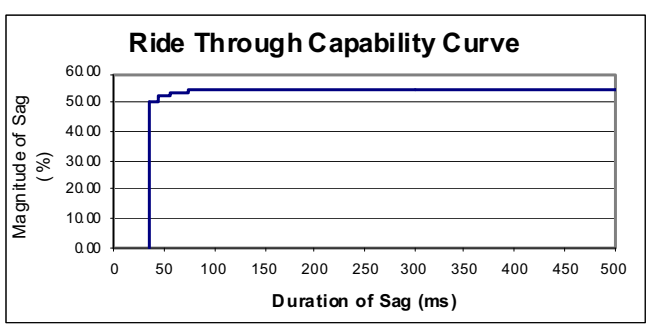

Figure 5. Ride through capability curve

Establishment of the MSSHIV can now be used to determine the impact of point-on-wave of sag initiation and phase shift of sag on ac contactor behavior.

TABLE I. SAMPLE SimULATION RESULTS

\begin{tabular}{|c|c|c|c|c|c|c|c|c|c|}
\hline $\begin{array}{c}\text { Duration } \\
(\mathrm{ms})\end{array}$ & \multicolumn{7}{|c|}{ Voltage Sag Magnitude (V \&\%) } \\
\cline { 2 - 12 } & 140 & 130 & 127 & 125 & 120 & 110 & 96 & 24 & 0 \\
\hline & 58.3 & 54.2 & 52.9 & 52.1 & 50.0 & 45.8 & 40.0 & 10.0 & 0.0 \\
\hline 20 & $\mathrm{E}$ & $\mathrm{E}$ & $\mathrm{E}$ & $\mathrm{E}$ & $\mathrm{E}$ & $\mathrm{E}$ & $\mathrm{E}$ & $\mathrm{E}$ & $\mathrm{E}$ \\
\hline 25 & $\mathrm{E}$ & $\mathrm{E}$ & $\mathrm{E}$ & $\mathrm{E}$ & $\mathrm{E}$ & $\mathrm{E}$ & $\mathrm{E}$ & $\mathrm{E}$ & $\mathrm{E}$ \\
\hline 30 & $\mathrm{E}$ & $\mathrm{E}$ & $\mathrm{E}$ & $\mathrm{E}$ & $\mathrm{E}$ & $\mathrm{E}$ & $\mathrm{E}$ & $\mathrm{E}$ & $\mathrm{E}$ \\
\hline 35 & $\mathrm{E}$ & $\mathrm{E}$ & $\mathrm{E}$ & $\mathrm{E}$ & $\mathrm{E}$ & $\mathrm{E}$ & $\mathrm{E}$ & $\mathrm{E}$ & $\mathrm{E}$ \\
\hline 40 & $\mathrm{E}$ & $\mathrm{E}$ & $\mathrm{E}$ & $\mathrm{E}$ & $\mathrm{E}$ & $\mathrm{D}$ & $\mathrm{D}$ & $\mathrm{D}$ & $\mathrm{D}$ \\
\hline 45 & $\mathrm{E}$ & $\mathrm{E}$ & $\mathrm{E}$ & $\mathrm{E}$ & $\mathrm{E}$ & $\mathrm{D}$ & $\mathrm{D}$ & $\mathrm{D}$ & $\mathrm{D}$ \\
\hline 50 & $\mathrm{E}$ & $\mathrm{E}$ & $\mathrm{E}$ & $\mathrm{E}$ & $\mathrm{D}$ & $\mathrm{D}$ & $\mathrm{D}$ & $\mathrm{D}$ & $\mathrm{D}$ \\
\hline 55 & $\mathrm{E}$ & $\mathrm{E}$ & $\mathrm{E}$ & $\mathrm{E}$ & $\mathrm{D}$ & $\mathrm{D}$ & $\mathrm{D}$ & $\mathrm{D}$ & $\mathrm{D}$ \\
\hline 60 & $\mathrm{E}$ & $\mathrm{E}$ & $\mathrm{E}$ & $\mathrm{D}$ & $\mathrm{D}$ & $\mathrm{D}$ & $\mathrm{D}$ & $\mathrm{D}$ & $\mathrm{D}$ \\
\hline 65 & $\mathrm{E}$ & $\mathrm{E}$ & $\mathrm{E}$ & $\mathrm{D}$ & $\mathrm{D}$ & $\mathrm{D}$ & $\mathrm{D}$ & $\mathrm{D}$ & $\mathrm{D}$ \\
\hline 70 & $\mathrm{E}$ & $\mathrm{E}$ & $\mathrm{D}$ & $\mathrm{D}$ & $\mathrm{D}$ & $\mathrm{D}$ & $\mathrm{D}$ & $\mathrm{D}$ & $\mathrm{D}$ \\
\hline 100 & $\mathrm{E}$ & $\mathrm{E}$ & $\mathrm{D}$ & $\mathrm{D}$ & $\mathrm{D}$ & $\mathrm{D}$ & $\mathrm{D}$ & $\mathrm{D}$ & $\mathrm{D}$ \\
\hline 300 & $\mathrm{E}$ & $\mathrm{E}$ & $\mathrm{D}$ & $\mathrm{D}$ & $\mathrm{D}$ & $\mathrm{D}$ & $\mathrm{D}$ & $\mathrm{D}$ & $\mathrm{D}$ \\
\hline 500 & $\mathrm{E}$ & $\mathrm{E}$ & $\mathrm{D}$ & $\mathrm{D}$ & $\mathrm{D}$ & $\mathrm{D}$ & $\mathrm{D}$ & $\mathrm{D}$ & $\mathrm{D}$ \\
\hline
\end{tabular}

2) Case 2- The impact of point-on-wave of sag initiation

The Point-on-wave of sag initiation is adjusted in step of $30^{\circ}$ in the range of $0^{\circ}$ up to $360^{\circ}$. For each adjusted voltage sag magnitude and point-on-wave, the duration of the sag is progressively increased until the contactor disengages or up to a one second. For all this point, the sag magnitude, duration and point-on-wave values are recorded. The simulation is performed that the sensitivity of ac contactor is repeated with the same influence at angles between $0^{\circ}$ and $180^{\circ}$.

Fig. 6 clearly shows the influence of the point-on-wave of sag initiation on ac contactor sensitivity when the entire curves are compared to the MSSHIV curve. The most sensitive of the ac contactor that is when $90^{\circ}$ point-on-wave was introduced during the voltage sag. This is shown by the area under the curve, which the $90^{\circ}$ curve presents the biggest area.

It is evident in Fig. 6 a voltage collapse at one point-onwave can have a very different effect on the ac contactor response when compared to identical voltage sag at another point-on-wave. Also, the difference in the critical sag duration for different point-on-wave can be as big as one cycle (20ms).

\section{3) Case 3- The impact of phase shift of sag}

The phase shift of sag is adjusted in step of $30^{\circ}$ in the range of $0^{\circ}$ to $90^{\circ}$ and $-90^{\circ}$. For each adjusted voltage sag magnitude and phase shift, the duration of the sag is progressively increased until the contactor disengages or up to one second.

Fig. 7 shows the most sensitive of the ac contactor when $-30^{\circ}$ phase shift is introduced during the sag compared to the MSSHIV curve. Therefore, it clearly shows the influence of phase shift on ac contactor performance. As can be seen in Fig. 7, the phase shift is influenced by the increase of the critical sag magnitude.

4) Case 4- Theimpact of point-on-wave and phase shift simultaneously

Fig. 8 shows the sensitivity of the ac contactor increases if $-30^{\circ}$ phase shift of sag and $90^{\circ}$ point-on-wave of sag initiation simultaneously are introduced during the sag.

Fig. 9 can be used for drawing conclusion of ac contactor performance during voltage sags. The most sensitive level is $57.5 \%$ remaining voltage of nominal voltage. Fig. 9 also shows the comparison of the entire curve for most sensitive of ac contactor with the SEMI F47 standard. Thus, it can be observed that the difference in the critical sag duration can be as big as one and a half cycle (30ms) and the difference in the critical sag magnitude can be as high as $8 \%$ within first $200 \mathrm{~ms}$ of duration.

As can be seen in Fig. 9, all curves become horizontal when approaching $60 \mathrm{~ms}$ duration. These values can be considered as the steady state characteristics of the ac contactor.

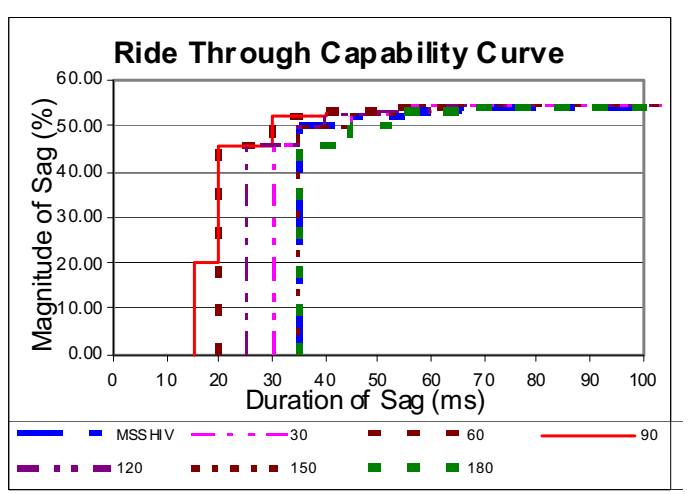

Figure 6. Influence of point-on-wave of sag initiation. 


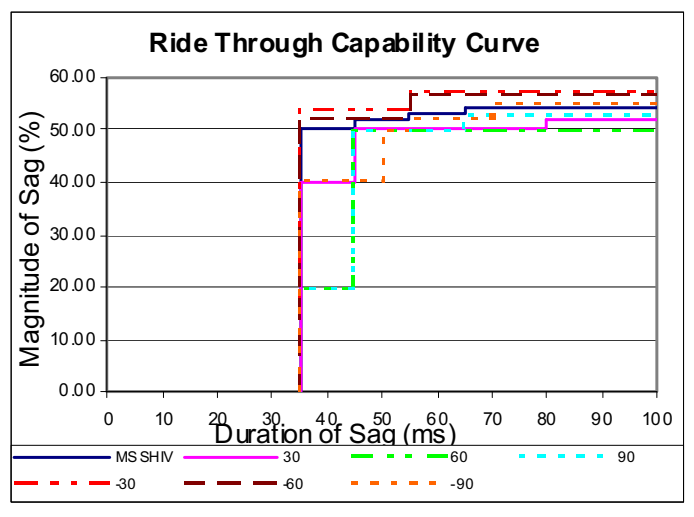

Figure 7. Influence of phase shift of sag

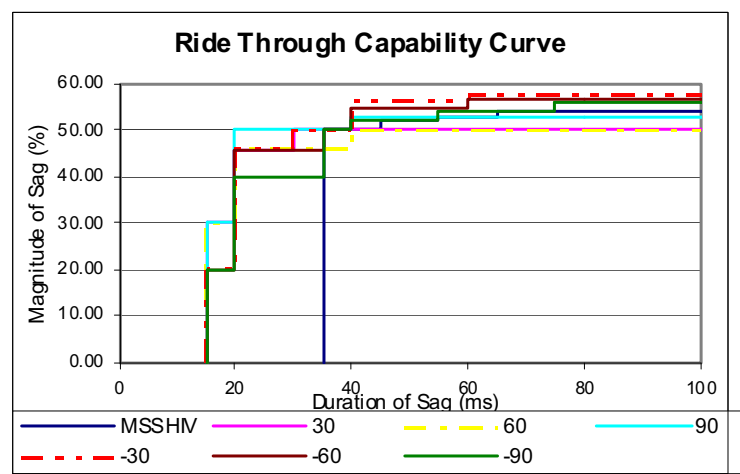

Figure 8. Influence of point-on-wave and phase shift simultaneously.

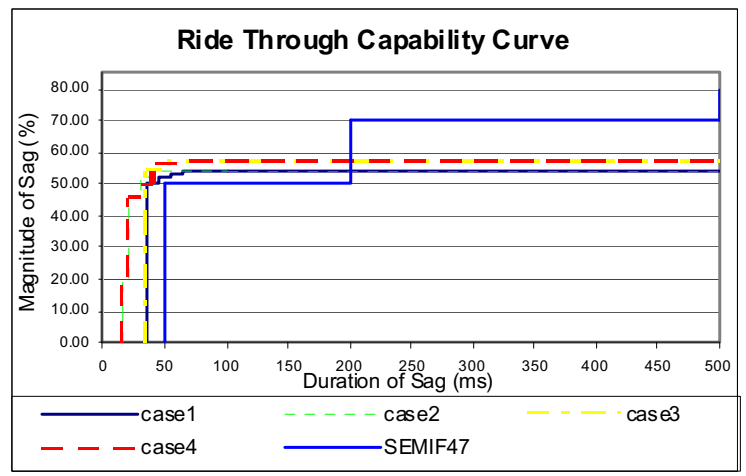

Figure 9. Comparison with SEMI F47

\section{CONCLUSION}

A detailed simulator tool for the sensitive analysis of ac contactor to voltage sags has been proposed. This paper describes the simulation procedure used to study and better understand the behavior of ac contactor when subjected to voltage sags. The ac contactor is expected to remain engaged if the magnitude of sag is equal or higher than the MSSHIV value. However from simulation results, the result has proven otherwise. Although at first glance certain magnitude of voltage sag with specific duration will always cause the ac contactor to disengage when the point-on-wave and phase shift is introduced during sags. Nevertheless, this clearly proves that ac contactor performances during sags is not solely dependent upon the sag magnitude and duration but also the point-on-wave and phase shift in which the voltage sag occurs as a very important aspect of ac contactors behavior. This study also produces some ride through capability curve to illustrate the worst case of voltage sags that can affect the performance of ac contactor. This is different from the existing standard of power a quality study, which does not include the point-on-wave and phase shift characteristics during the construction of the ride through capability curve. By having this simulator tool, the sensitivity of practical ac contactor can be identified without having to perform laboratory experiments.

For assessing the process sensitivity, single device type performance data is needed. The ride through capability curve over each of the sensitive equipment will assist the customers to determine the minimum supply for the equipment to operate. Therefore, it will improve the operation of the sensitive equipment.

\section{ACKNOWLEDGMENT}

Noor azila Ismail gratefully acknowledges the assistance rendered by the Faculty of Electrical Engineering, Universiti Teknologi MARA, Malaysia in work reported in this paper.

\section{REFERENCES}

[1] Bollen M. H. J.,'Understanding power quality problem; voltage sag and interruptions", New York:IEEE Press, 2000, Series on Power Engineering.

[2] E. R. Collins, M. A. Bridgwood, "The Impact of Power System Disturbances on AC-Coil Contactors", Proc. IEEE Textile, Fiber Film Ind. Tech. Annu. Conf., Greenville, SC, Page(s): 2 - 6, May 6-8, 1997.

[3] P. Pohjanheimo, M. Lehtonen, "Equipment Sensitivity to Voltage Sags - Test Results for Contactors, PCs and Gas Discharge Lamps", IEEE Harmonics and Quality of Power, $10^{\text {th }}$ International Conference, Vol. 2, Page(s): 559 - 564, 6 - 9 Oct. 2002.

[4] Mohamad H., Khalid M. Nor, "Evaluation on Sensitivity of AC Contactor during Voltage Sags", TENCON 2004, 2004 IEEE Region 10 Conference, Volume C, Nov. 21-24, 2004, Page(s): 295-298.

[5] Bansidhar E. Kushare, Ashok A. Ghatol, "Investigation of Cost Effective Method to Improve Voltage Sag Ride Through Capability of AC Coil Contactors", IET-UK International Conference on Information and Communication Technology in Electrical Sciences (ICTES 2007), Dr. M.G.R University, Chennai, Tamil Nadu, India. Dec. 20-22, 2007. pp. 425-457.

[6] PSCAD User Guide; http://www.pscad.com/

[7] A. E. Turner, E. R. Collins, "The Performance of Ac Contactors during Voltage Sags", $7^{\text {th }}$ Int. Conf. on Harmonics and Quality of Power, Los Vegas, NV, Page(s): 589-595, October 1996.

[8] IEEE Recommended practice for powering and grounding sensitive electronic equipments (Emerlad book), IEEE Std. 1100, 1992

[9] Collins E.R., Zapardiel F., “An Experimental Assessment of Ac Contactor Behavior during Voltage Sags", ISIE '97, Proceedings of the IEEE International Symposium on Industrial Electronics, 1997, Vol.2, Page (S): 439 -444, 1997.

[10] Michael A. Bridgwood, Mark Stephens, "An Assessment of the Susceptibility of A.C. Contactors following Supply Voltage Sags", Power Quality Proceedings, Page(s): 466-474, November 1999.

[11] SEMI F47 Specifications for semiconductor equipment voltage sag immunity, semiconductor equipment and material international Std. 